\title{
AN AGENT-BASED MODEL TO REPRESENT SPACE-TIME PROPAGATION OF FOREST-FIRE SMOKE
}

\author{
A. K. Smith, S. Dragicevic \\ Spatial Analysis and Modeling (SAM) Lab, Department of Geography, \\ Simon Fraser University, Burnaby, Canada - (aksmith, suzanad)@sfu.ca
}

Commission IV, WG IV/8

KEY WORDS: Agent-Based Modeling, Space-Time Modeling, Geographic Automata, Simulation Model, Complex Systems, ForestFire Smoke Propagation

\begin{abstract}
:
Agent-based modeling approaches have been used for various case studies related to the geospatial dynamics of complex systems. The proliferation of forest-fire smoke and the associated airborne particulate matter that behaves as complex systems make it important to develop reliable geospatial models that can simulate the propagation process to avoid impacts to human health and the environment. Therefore, the main objective of this research study is the development and implementation of an agent-based model (ABM) for the propagation of forest-fire smoke and other airborne particulate matter for use in studying patterns of spatio-temporal propagation. The developed ABM operates on a two-dimensional plane in the landscape where agents representing forest fires emit agents representing smoke. These smoke agents propagate through the study area based on measured atmospheric conditions. The model was developed using data from the 2017 forest fire season in British Columbia (BC) and parts of Alberta, Canada, particularly during the period August $10^{\text {th }}-25^{\text {th }}$. The obtained simulation results provided patterns of spatio-temporal propagation of fire smoke over large areas of $\mathrm{BC}$ and Alberta, and were compared to the real smoke patterns covering the Edmonton metropolitan area, Canada on a similar date. The developed agent-based model can be used to support the emergency planning and decision-making process such as in regulating forest fire evacuations and in the prevention of health problems triggered by the exposure to smoke.
\end{abstract}

\section{INTRODUCTION}

Forest fire severity and frequency increases with climate change and in turn contributes to the global climate change process (Running, 2006; van Mantgem et al., 2013; Westerling, 2006) leading to adverse effects on environment and human health. The 2017 fire season in British Columbia, Canada (BC) was one of the worst in BC's history. The forest fires caused a 70-day long provincial state of emergency, the longest in BC's history, and the first since 2003 (B.C. Wildfire Service, 2018). The BC Wildfire Service (2018) reports that over 1.2 million hectares burned and 65,000 people displaced during the 2017 fire season. In 2003, an increase in physician visits for respiratory related illnesses in $\mathrm{BC}$ was attributed to the forest fires during that year (Dennekamp and Abramson, 2011).

In order to decrease smoke exposure, the BC Centre for Disease Control advises people to stay indoors and reduce physical activity during smoke events (Elliott, 2014). Different measures have to be established to better assist inhabitants in low and high dense urban areas affected by the hazards of smoke propagation (Henderson et al., 2011). The understanding, modeling and forecasting of the spatial dispersion of forest fire smoke is important because these can provide additional information for the emergency planning and decision-making process regulating forest fire evacuations, for advance warnings systems to limit exposure and for preventing health issues triggered by smoke.

Forest-fire smoke models have been developed implementing various modeling methods and are predominantly numerical. One such modeling approach is the Weather Research and Forecasting with Chemistry (WRF-Chem) model that is capable of simulating forest fire smoke propagation (Grell et al., 2005). WRF-Chem combines various atmospheric and chemical models into one fully-coupled model to investigate and forecast the concentrations of trace gas and particulates, such as smoke, in the atmosphere (Grell et al., 2005). BlueSky, another smoke forecasting system, was developed by the U.S. Forest Service which implements the Hybrid Single Particle Lagrangian Integrated Trajectory (HYSPLIT) model (Rolph et al., 2009). The HYSPLIT model calculates smoke concentrations using methods from the Lagrangian and Eulerian views of fluid motion (Rolph et al., 2009). Smoke within HYSPLIT uses both movement and change to model smoke parcels which may grow, expand, and split depending on the atmospheric conditions (Escudero et al., 2006).

While these existing modeling approaches are used by officials as smoke forecasting systems, they have some disadvantages. They do not represent smoke propagation as a continuous gradient of smoke concentration while using Lagrangian movement. The WRF-Chem does model smoke as a gradient of concentration (Grell et al., 2005) but it does not use Lagrangian movement and restricts the capability of the movement of smoke. HYSPLIT does use Lagrangian movement (Rolph et al., 2009) but uses parcels of smoke instead of a gradient and this does not allow for smoke in the same area to be affected differently by the propagation processes. Creating a model that can incorporate both components would allow for the simulation of the interactions between smoke particles, the atmosphere, and the topography. A complex systems approach using the agentbased modelling (ABM) method can incorporate the two components and represent the actual geospatial process and individual interaction of smoke particles for propagation. In this study, the main objective was to develop an ABM approach for representing the spatial dynamics of the propagation of forestfire smoke. The model development used datasets of measured atmospheric conditions during the 2017 forest fire season during the period of August $10^{\text {th }}-25^{\text {th }}$ in British Columbia (BC) and parts of Alberta, Canada. 


\section{THEORETICAL BACKGROUND}

Geographical systems such as forest fires, land use and land cover change, and insect infestation, are often seen as complex systems as they are composed of multiple elements that interact among themselves and the environment in a nonlinear way, and thus are difficult to predict (Manson, 2001). The mathematical representation of complex systems can be operationalized with the theory of geographic automata systems (GAS) that compose two main approaches - cellular automata (CA) and agent-based modeling methods (Torrens and Benenson, 2005). These modeling methods are capable of capturing the complexity of geospatial processes at small or very fine geographic scales and propagating the resulting patterns at much larger or coarser spatial scales (Manson, 2001). Moreover, geospatial data commonly available from remote sensing (RS) and geographic information systems (GIS) can be used as GAS model input to realistically represent the dynamics of geographical processes. Particularly, ABM approaches have been used to represent the behavior and interactions of several individuals such as pedestrian movements (Zhu and Timmermans, 2011), land market and land use change (Filatova et al., 2013; Parker et al., 2003), urban growth (Kocabas and Dragicevic, 2013), forest insect infestations (Anderson and Dragićević, 2015; Pérez and Dragićević, 2011), animal behavior (Bonnell et al., 2013) and human disease propagation (Perez and Dragicevic, 2009) to name a few. Further, to model ecological and coupled humanenvironment systems, GAS models were used in physical processes including hydrology (Reaney, 2008), soil erosion (Heung et al., 2013), forest fires (Clarke et al., 1994; Hsu and W. S. Liu, 2015; Yassemi et al., 2008) sand dune patterns (Genois et al., 2013), and airborne particle propagation (Jjumba and Dragićević, 2015)

In the GAS models, CA and ABM can be explained as a bottomup modeling approach where small-scale processes are defined within the model and large-scale processes and patterns emerge during model processing (Crooks et al., 2008). The CA typically uses a grid of cells or rasters, where the state of each cell depends on the state of other nearby cells and governed by an established transition ruleset (White and Engelen, 2000). However, the ABM depends on small software routines or segments of code that are called 'agents' and are responsible for the decision-making process of interactions and behavior of real world entities being represented. Agents interact with each other and the environment to reach the goals that are set as priority. The ABMs can be coupled with other equation models which distinguishes them from other models such as statistical or only equations-based models that limits the capability to represent the spatio-temporal dynamics and spatial pattern of change (Brown et al., 2005).

Both $\mathrm{CA}$ and $\mathrm{ABM}$ approaches can be used to spatially represent the smoke propagation phenomenon. For the modeling of smoke propagation, the cell states describe the concentration of smoke and change with each iteration of the rules depending on the wind patterns and concentration of smoke upwind (Yassemi et al., 2008). The challenge with using a CA is the inability to represent mobility of individual particles and their interactions that compose the smoke, thus cannot adequately capture the smoke propagation process in both space and time. Therefore, the ABM approach is better suited for simulation modeling of the forest-fire smoke and airborne particle matter propagation as it can represent individual particles interactions and behaviour of the overall process from very fine to coarse scales. Moreover, Brown et al. (2005) indicate that ABM can incorporate both the
Lagrangian perspective as the description of movement and the Eulerian perspective as the description of change.

\section{METHODS}

\subsection{Model Overview}

The flowchart of the proposed ABM model is presented in Figure 1. The atmospheric conditions, wind speed, direction, and atmospheric pressure together with the elevation have all been used as the model input. The atmospheric conditions are reported as pressure isosurfaces that does not represent the elevation but instead a surface of constant pressure. The choice of elevation needs to be specified during model setup to define the modeling plane and calculate the atmospheric conditions along the plane. The model is composed of two types of agents - the fire and the smoke agents. The main purpose of the fire agents is to generate smoke agents that are emitted from a fire. The fire agents determine the overall number of smoke agents released to the atmosphere for simulation of the smoke particles propagation process. This is regulated by a variable that can change to accommodate the number and intensity of the fire events represented by the model. In scenarios with multiple fires, at

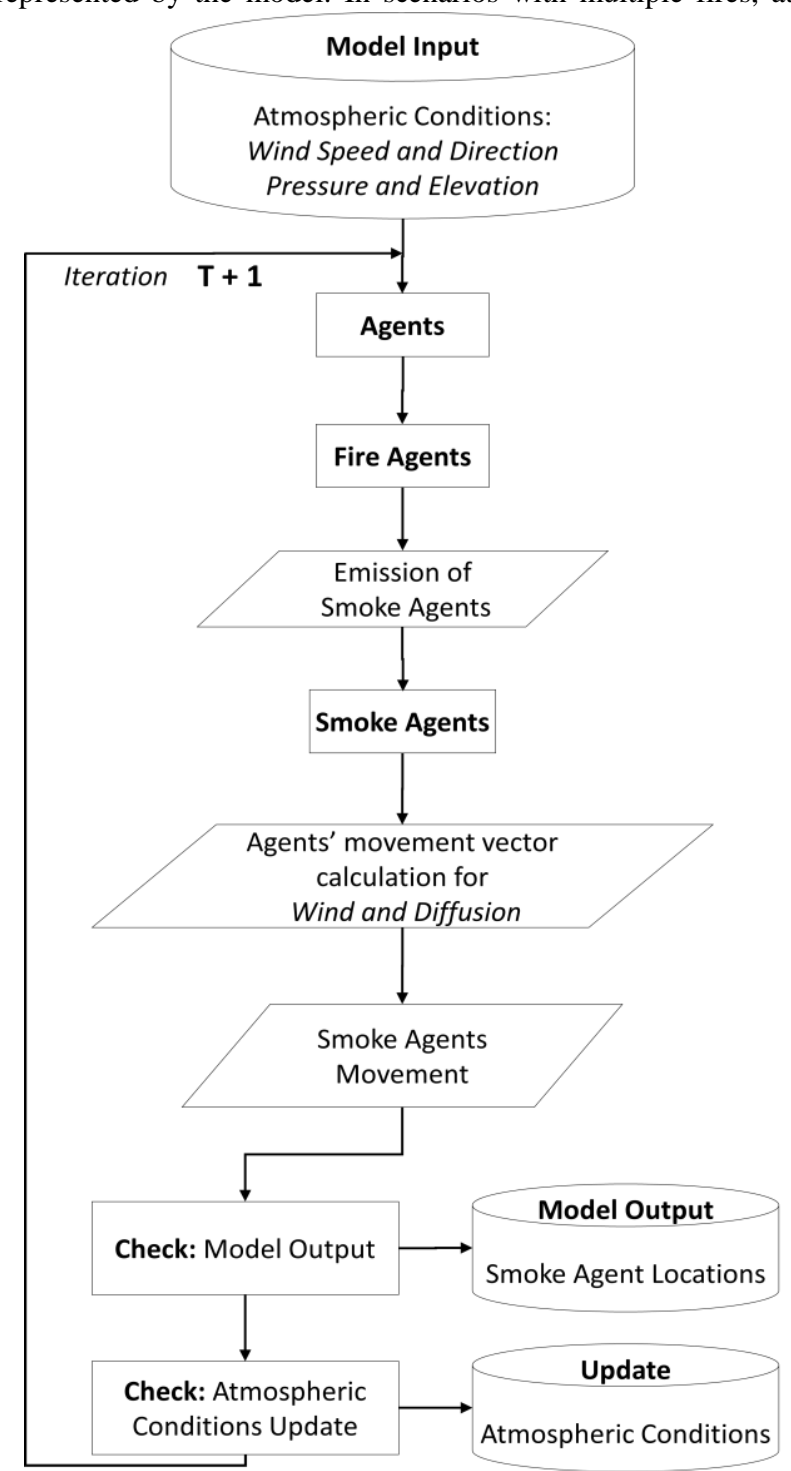

Figure 1 - Flowchart of the agent-based model of forest-fire smoke propagation 
least one fire agent must be located at each fire. The smoke agents incorporate the Lagrangian movement as vector of movement of the smoke particles after they are emitted into the atmosphere. The smoke agents move using two simultaneous processes, diffusion and wind. Both processes are calculated using the same atmospheric conditions and before any movement occurs. The movement of smoke agents occurs at a time interval called the processing resolution.

The diffusion occurs when smoke agents move from areas of higher smoke density to areas of lower smoke density (Kellogg, 1956). In order to calculate diffusion the agent uses nearby agents and the modeling grid of cells, or the neighbourhood, to determine smoke density. If the smoke agent is in the densest cell in the neighbourhood it will select a random direction to move. If the agent is not in the densest cell, it will move directly away from that cell. The distance to move in both cases is determined during the calibration of the model for the specific scenario. Diffusion is essential to the model because it spreads the smoke across the landscape. If diffusion did not occur, the smoke would stay in a narrow plume and would not produce realistic spread patterns. The direction and distance to move is saved in the model as the diffusion movement vector for use after the wind movement vector has been calculated.

The diffusion process consists of two components - the distance to diffuse from the original cell and the surrounding neighbourhood - and so the model calibration is needed. Depending on the processing resolution for the modeling process and the number of smoke agents, these values need to be adjusted. The proposed ABM model calibration was done to adjust to the measurements from the High Altitude Dust Diffusion study (Kellogg, 1956). This study was chosen because it measured dispersion in stable air, thus the measured diffusion was not affected by the turbulence in the air. The ABM calibration has been achieved to make the smoke diffuse to a spread diameter of approximately $100 \mathrm{~m}$ in 4 minutes and $150 \mathrm{~m}$ after 10 minutes.

Movement by wind depends on the measured past atmospheric conditions or forecasted future atmospheric conditions, and it is directly obtained from the atmospheric condition dataset. The smoke agents use the wind speed and direction vectors to calculate locations where to move. The wind speed in meters per second needs to be converted into fractions of a cell per time step. Finally, the wind movement and diffusion movement vectors are added, and the agent moves to the new location designated by this new vector. After movement, the model checks for two conditions. First, the time to determine if a model output is scheduled. Second, it checks if new set of atmospheric conditions are available.

The software Repast Simphony (North et al., 2013) with the Java programming language was used to implement the ABM model. The ABM is loosely-coupled with the ArcGIS software (ESRI, 2018) for the purpose of the visualisation of the model outputs. The series of simulation outputs are mapped to represent the spatial dynamics of the smoke pattern propagation over the landscape.

\subsection{Study area and datasets}

In order to implement a sample scenario of the agent-based model, Southern British Columbia and parts of Alberta, Canada were chosen as the study area given the extensive forest fires during the summer 2017. The metropolitan areas of Vancouver, Seattle, Edmonton, and Calgary were severely affected during the 2017 forest fire season for multiple days with high smoke concentrations.

Atmospheric conditions were obtained from the National Centers for Environmental Prediction (NCEP) in the form of the North American Regional Reanalysis (National Centers for Environmental Prediction et al., 2005). This dataset contains atmospheric conditions at 29 pressure levels of the atmosphere with a horizontal resolution of $32 \mathrm{~km}$. Each layer represents one pressure isosurface, where all data in the layer represents conditions at the same pressure, although the elevation varies. While there are many variables in the dataset, the ones used in this study include the wind speed, wind direction, pressure, and elevation as specified in the model input. Wind speed and direction are in the form of north/south (u) and the east/west (v) wind vectors. These are converted into meters per second for speed and degrees from north for direction as required by the model. This dataset is updated every three hours and is created by averaging the conditions over the three hours.

\section{SIMUALTION RESULTS}

The temporal resolution used is 3 hours due to the atmospheric conditions data and the model processing resolution is 1 minute. The spatial resolution of the model was $100 \mathrm{~m}$ with the diffusion neighbourhood of five cells as it produced accurate diffusion results during calibration.

The initialisation of the agent-based model was set to correspond to the hypothetical fire located at the hill north of Khartoum Lake (49.900 N, -124.118 E); approximately $100 \mathrm{~km}$ northwest of the Metro Vancouver region to start on August 10 $0^{\text {th }}, 2017$ at $12 \mathrm{am}$ and end on August 25 $5^{\text {th }}, 2017$ at 12pm. This location was chosen because the wind data during the selected period was available and because it closely corresponded to the actual fire events in reality. Simulation results are generated every three hours for 15 days, which involved a total of 21,240 model iterations. The fire was set to an elevation of $1,000 \mathrm{~m}$. The simulations that represent 15 days of smoke propagation took 4 hours and 20 minutes to process using an Intel Xeon E5-2620 v4 CPU with 64 GB RAM. Figure 2 presents the results of the simulation outcomes in the morning of the second (August $12^{\text {th }}$ ), fourth (August $14^{\text {th }}$ ), sixth (August $16^{\text {th }}$ ), and eighth (August $18^{\text {th }}$ ) day of smoke propagation in British Columbia and part of Alberta.

At the beginning of the simulation, the smoke remains trapped in the areas of the straits of Georgia and Johnstone for approximately two days (+2 Days in Figure 2). Later the smoke was propagated towards north-northeast and separates into two plumes (+4 Days in Figure 2). By the sixth day, the northern plume has left the northeast and the southern plume is exiting towards the east (+6 Days in Figure 2). After eight days, the smoke is covering the Metropolitan area of Edmonton although it quickly passes ( +8 Days in Figure 2$)$ due to wind patterns. The visual comparison has been made for similar date to reports of smoke alerts for the Edmonton metropolitan area.

\section{CONCLUSIONS}

The proposed agent-based model uses real geospatial and atmospheric data together with realistic physical process generation in order to demonstrate the potential of the GAS approach for representing forest-fire smoke propagation through the atmosphere at a large geographic scale. 


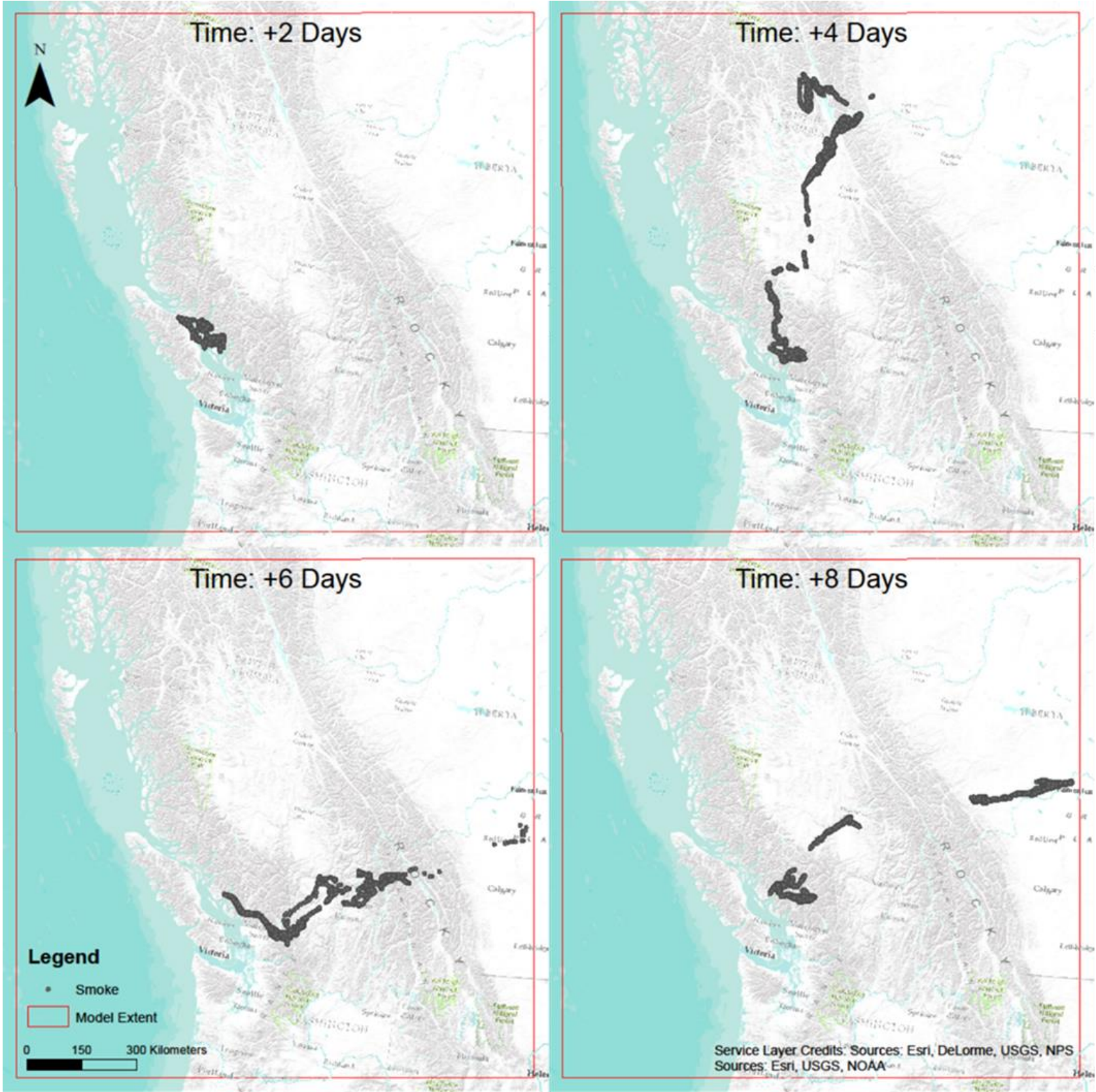

Figure 2 - Simulation results of the smoke propagation patterns initialized with the forest fire near Khartoum Lake, BC and with snapshots captured for days 2, 4, 6 and 8

The developed $\mathrm{ABM}$ has the capability to forecast spatiotemporal pattern of the smoke dispersion initiated from a specific fire event. The simulated patterns of smoke propagation are similar to those observed in satellite and aerial images. Moreover, the proposed model is capable of handling multiple fire events and combining the smoke dispersion from different locations of forest fires as is often the case in nature. For the purposes of this research study, the hypothetical fire near Khartoum Lake was set for the initiation of the modelling procedure, however more accurate information of the location of actual forest fire ignition can be used to initiate the model. The obtained simulations have demonstrated that the smoke particles have been realistically propagated and impacted air quality for the major urban centres of British Columbia and Alberta. Additionally, Edmonton metropolitan area, Alberta experienced days with poor air quality due to forest fire smoke at the same time as demonstrated by the model.

However, the proposed ABM needs further enhancement and full model calibration and validation to be able to realistically forecast the smoke propagation and thus be used for decisionmaking purposes. Primarily, better atmospheric data is needed as the data currently used is too coarse to accurately model movement through smaller mountain valleys. While some valleys are several kilometres across, the wind data has a raster cell size of $32 \mathrm{~km}$. The smoke will still pass through the valley but the variations in wind caused by the terrain will not be accounted for. Secondly, the exact location of the forest fire and the amount of smoke being released would also be beneficial. Obtaining data for smoke density has proven to be difficult and the best alternative found is a combination of meteorological station recordings of airborne particulate matter and satellite imagery for the days being modeled. Satellite imagery alone are not enough for validation procedures as they do not include smoke concentrations and the imagery may be processed to eliminate smoke from other sources and clouds. Finally, the addition of terrain data, in the form of a digital elevation model at high resolution, would permit the development of an improved ABM that can operate in $3 \mathrm{D}$. Such an enhanced model would be 
able to simulate smoke propagation at different elevations and use the terrain features to influence the actual movements.

Nevertheless, the proposed ABM incorporates the Lagrangian movement and the smoke gradient as part of the smoke agents during their movement in the space, and therefore represents the actual dynamics of the process. The model can be also applied to forecast movement smoke from other sources such as hazardous pollution from a factory or urban pollution. With advanced calibration and validation, the developed $\mathrm{ABM}$ has the potential to be used in official alerts and warnings systems to prevent or mitigate the dangers of smoke exposure.

\section{ACKNOWLEDGMENTS}

This study was fully funded by a Natural Sciences and Engineering Research Council (NSERC) of Canada Discovery Grant awarded to the second author. The authors thank their colleague for the assistance with the Repast Simphony software. Authors are thankful to three anonymous reviewers for valuable feedback.

\section{REFERENCES}

Anderson, T., Dragićević, S., 2015. An agent-based modeling approach to represent infestation dynamics of the emerald ash borer beetle. Ecol. Inform. 30, 97-109. https://doi.org/10.1016/j.ecoinf.2015.09.003

B.C. Wildfire Service, 2018. Wildfire Season Summary [WWW Document]. Prov. Br. Columbia. URL https://www2.gov.bc.ca/gov/content/safety/wildfirestatus/about-bcws/wildfire-history/wildfire-season-summary (accessed 4.30.18)

Bonnell, T.R., Dutilleul, P., Chapman, C.A., Reyna-Hurtado, R., Hernández-Sarabia, R.U., Sengupta, R., 2013. Analysing small-scale aggregation in animal visits in space and time: The ST-BBD method. Anim. Behav. 85, 483-492. https://doi.org/10.1016/j.anbehav.2012.12.014

Brown, D.G., Riolo, R., Robinson, D.T., North, M., Rand, W., 2005. Spatial process and data models: Toward integration of agent-based models and GIS. J. Geogr. Syst. 7, 25-47. https://doi.org/10.1007/s10109-005-0148-5

Clarke, K.C., Brass, J. a, Riggan, P.J., 1994. A CellularAutomaton Model of Wildfire Propagation and Extinction. Photogramm. Eng. Remote Sensing 60, 1355-1367.

Crooks, A., Castle, C., Batty, M., 2008. Key challenges in agent-based modelling for geo-spatial simulation. Comput. Environ. Urban Syst. 32, 417-430.

https://doi.org/10.1016/j.compenvurbsys.2008.09.004

Dennekamp, M., Abramson, M.J., 2011. The effects of bushfire smoke on respiratory health. Respirology 16, 198-209. https://doi.org/10.1111/j.1440-1843.2010.01868.x

Elliott, C., 2014. Guidance for BC Public Health Decision Makers During Wildfire Smoke Events.

Escudero, M., Stein, A., Draxler, R.R., Querol, X., Alastuey, A., Castillo, S., Avila, A., 2006. Determination of the contribution of northern Africa dust source areas to PM10 concentrations over the central Iberian Peninsula using the
Hybrid Single-Particle Lagrangian Integrated Trajectory model (HYSPLIT) model. J. Geophys. Res. Atmos. 111, 1-15. https://doi.org/10.1029/2005JD006395

ESRI, 2018. ArcGIS Desktop: Release 10.5.

Filatova, T., Verburg, P.H., Parker, D.C., Stannard, C.A., 2013. Spatial agent-based models for socio-ecological systems: Challenges and prospects. Environ. Model. Softw. 45, 1-7. https://doi.org/10.1016/j.envsoft.2013.03.017

Genois, M., Du Pont, S.C., Hersen, P., Gregoire, G., 2013. An agent-based model of dune interactions produces the emergence of patterns in deserts. Geophys. Res. Lett. 40, 39093914. https://doi.org/10.1002/grl.50757

Grell, G.A., Peckham, S.E., Schmitz, R., McKeen, S.A., Frost, G., Skamarock, W.C., Eder, B., 2005. Fully coupled "online" chemistry within the WRF model. Atmos. Environ. 39, 69576975. https://doi.org/10.1016/j.atmosenv.2005.04.027

Henderson, S.B., Brauer, M., MacNab, Y.C., Kennedy, S.M., 2011. Three measures of forest fire smoke exposure and their associations with respiratory and cardiovascular health outcomes in a population-based cohort. Environ. Health Perspect. 119, 1266-1271. https://doi.org/10.1289/ehp.1002288

Heung, B., Bakker, L., Schmidt, M.G., Dragićević, S., 2013. Modelling the dynamics of soil redistribution induced by sheet erosion using the Universal Soil Loss Equation and cellular automata. Geoderma 202-203, 112-125. https://doi.org/10.1016/j.geoderma.2013.03.019

Hsu, T.-L., W. S. Liu, J., 2015. ABDiSE: Agent-Based Disaster Simulation Environment. Int. J. Model. Optim. 5, 374-380. https://doi.org/10.7763/IJMO.2015.V5.491

Jjumba, A., Dragićević, S., 2015. Integrating GIS-Based GeoAtom Theory and Voxel Automata to Simulate the Dispersal of Airborne Pollutants. Trans. GIS 19, 582-603.

https://doi.org/10.1111/tgis.12113

Kellogg, W.W., 1956. Diffusion of Smoke in the Stratosphere. J. Meteorol. 13, 241-250.

Kocabas, V., Dragicevic, S., 2013. Bayesian networks and agent-based modeling approach for urban land-use and population density change: A BNAS model. J. Geogr. Syst. 15, 403-426. https://doi.org/10.1007/s10109-012-0171-2

Manson, S.M., 2001. Simplifying complexity: A review of complexity theory. Geoforum 32, 405-414. https://doi.org/10.1016/S0016-7185(00)00035-X

National Centers for Environmental Prediction, National Weather Service, NOAA, U.S. Department of Commerce, 2005. NCEP North American Regional Reanalysis (NARR), Research Data Archive at the National Center for Atmospheric Research, Computational and information Systems Labratory [WWW Document]. URL http://rda.ucar.edu/datasets/ds608.0/ (accessed 3.11.17)

North, M.J., Collier, N.T., Ozik, J., Tatara, E.R., Macal, C.M., Bragen, M., Sydelko, P., 2013. Complex adaptive systems modeling with Repast Simphony. Complex Adapt. Syst. Model. 1, 3. https://doi.org/10.1186/2194-3206-1-3 
Parker, D.C., Manson, S.M., Janssen, M.A., Hoffmann, M.J., Deadman, P., 2003. Multi-agent systems for the simulation of land-use and land-cover change: A review. Ann. Assoc. Am. Geogr. 93, 314-337. https://doi.org/10.1111/14678306.9302004

Perez, L., Dragicevic, S., 2009. An agent-based approach for modeling dynamics of contagious disease spread. Int. J. Health Geogr. 8, 1-17. https://doi.org/10.1186/1476-072X-8-50

Pérez, L., Dragićević, S., 2011. ForestSimMPB: A swarming intelligence and agent-based modeling approach for mountain pine beetle outbreaks. Ecol. Inform. 6, 62-72. https://doi.org/10.1016/j.ecoinf.2010.09.003

Reaney, S.M., 2008. The use of agent based modelling techniques in hydrology: determining the spatial and temporal origin of channel flow in semi-arid catchments. Earth Surf. Process. Landforms 33, 317-327. https://doi.org/10.1002/esp

Rolph, G.D., Draxler, R.R., Stein, A.F., Taylor, A., Ruminski, M.G., Kondragunta, S., Zeng, J., Huang, H.-C., Manikin, G., McQueen, J.T., Davidson, P.M., 2009. Description and Verification of the NOAA Smoke Forecasting System: The 2007 Fire Season. Weather Forecast. 24, 361-378. https://doi.org/10.1175/2008WAF2222165.1

Running, S.W., 2006. Is global warming causing more, larger wildfires? Science (80-. ). 313, 927-928.

https://doi.org/10.1126/science.1130370
Torrens, P.M., Benenson, I., 2005. Geographic Automata Systems. Int. J. Geogr. Inf. Sci. 19, 385-412. https://doi.org/10.1080/13658810512331325139

van Mantgem, P.J., Nesmith, J.C.B., Keifer, M., Knapp, E.E., Flint, A., Flint, L., 2013. Climatic stress increases forest fire severity across the western United States. Ecol. Lett. 16, 11511156. https://doi.org/10.1111/ele.12151

Westerling, A.L., 2006. Warming and Earlier Spring Increase Western U.S. Forest Wildfire Activity. Science (80-. ). 313, 940-943. https://doi.org/10.1126/science.1128834

White, R., Engelen, G., 2000. High-resolution Integrated Modelling of the Spatial Dynamics of Urban and Regional Systems. Comput. Environ. Urban Syst. 24, 383-400. https://doi.org/10.1016/S0198-9715(00)00012-0

Yassemi, S., Dragićević, S., Schmidt, M., 2008. Design and implementation of an integrated GIS-based cellular automata model to characterize forest fire behaviour. Ecol. Modell. 210, 71-84. https://doi.org/10.1016/j.ecolmodel.2007.07.020

Zhu, W., Timmermans, H., 2011. Modeling pedestrian shopping behavior using principles of bounded rationality: Model comparison and validation. J. Geogr. Syst. 13, 101-126. https://doi.org/10.1007/s10109-010-0122-8 